\title{
Influence of Substrates and Hydrogels on Spearmint (Mentha spicata) Growth and Flowering in a Rooftop Garden
}

\author{
Jin-Hee Ju and Yong-Han Yoon \\ Department of Green Technology Convergence, College of Science, \\ KonKuk University-Glocal Campus, 268, Chungwondaero, Chungju-si, \\ Chungcheongbuk-do, 27487, South Korea
}

\author{
Se-Young Ju \\ Division of Food Bioscience, College of Biomedical and Health Science, \\ KonKuk University-Glocal Campus, 268, Chungwondaero, Chungju-si, \\ Chungcheongbuk-do, 27487, South Korea
}

Additional index words. growing medium, herb growth, rooftop farming, urban sustainability, water retention additives

\begin{abstract}
Agricultural hydrogels improve water retention in a variety of substrates. However, little is known about their impact on herb cultivation in rooftop farming. To identify the optimal substrate and hydrogel concentration for the growth and flowering of spearmint (Mentha spicata) in rooftop gardens, coir and perlite were mixed in three different ratios of $80 \%$ to $20 \%$ (v/v; referred to as $\left.\mathrm{C}_{4} \mathrm{P}_{1}\right), 50 \%$ to $50 \%$ $\left(C_{1} P_{1}\right)$, or $20 \%$ to $80 \%\left(C_{1} P_{4}\right)$. Hydrogels were added into different substrates at different concentrations including 0 (control), $0.25,0.5,1.0$, or $2.0 \mathrm{~kg} \cdot \mathrm{m}^{-3}$. Substrate composition significantly affected the growth $(P<0.001)$ and flowering $(P<0.05)$ properties of spearmint. The addition of hydrogels into substrates resulted in a significant $(P<0.05)$ increase in growth parameters for spearmint during the dry season. However, plants grown in $\mathrm{C}_{4} \mathrm{P}_{1}$, which has the highest ratio of coir, displayed inferior growth and flowering compared with those of the other two substrates during the rainy season. Therefore, a perlite-based substrate, such as $C_{1} P_{4}$ with added hydrogel, provides a suitable environment for the cultivation of spearmint in rooftop gardens regardless of seasonal rainfall patterns.
\end{abstract}

Green roofs have numerous environmental benefits as well as provide green and open spaces without requiring additional land. In recent years, rapid urbanization and the rise of urban agriculture have led to increased interest in the development of green roofs (Getter and Rowe, 2006). More and more edible plants are grown in green roof gardens not only for their ecological effects, but also for the social benefits of supplying safe and adequate nutrition. Rooftop farming can provide a solution to increased food demand in addition to helping create a sustainable and livable city (Mastura et al., 2017). In researching green roofs, it is important to consider the climate specifications of the region when choosing the growing medium, soil depth, and other substrate attributes to ensure proper plant performance (Fatemeh and Ruzica, 2017). In particular, green roofs in temperate climates are frequently exposed to periodic drought and rapid fluctuations in

Received for publication 6 Nov. 2020. Accepted for publication $15 \mathrm{Jan} .2021$.

Published online 19 May 2021

Y.-H.Y. is the corresponding author. E-mail: yonghan7204@kku.ac.kr.

This is an open access article distributed under the CC BY-NC-ND license (https://creativecommons. org/licenses/by-nc-nd/4.0/). moisture availability resulting from the shallow depth and low water content in the substrate.

Agricultural hydrogels are cross-linked crystalline forms of insoluble polymers, typically polyacrylamide, that absorb and store water up to 500 times their own weight when saturated, and thus are widely used to improve the moisture content of soil in the fields of agriculture, horticulture, and forestry (Farrell et al., 2013). Hydrogels have been shown previously to prolong survival times and increase plant morphological and physiological characteristics in drought conditions (Orikiriza et al., 2013; Tomadoni et al., 2020). Accordingly, there are studies that have assessed the effects of hydrogel mixed substrates and their relationship to plant growth (Farrell et al., 2013; Olszewski et al., 2010; Savi et al., 2015). However, these studies ' have focused mainly on the physicochemical properties of the substrates and drought-resistant plants, including succulents, grasses, legumes, and shrubs. Some studies have suggested that hydrogels have no effect on the growth and physiological parameters of drought-resistance species grown on green roofs (Apostol et al., 2009). To the best of our knowledge, very little research has been published on the benefits of hydrogel addition to substrates for herb cultivation in green roofs according to regional climatic conditions (Ju et al., 2020; Savi et al.,
2014; Xu et al., 2018). Therefore, there is a need to discover more plants suitable for rooftop gardening to improve both ornamental value and biodiversity.

Spearmint (Mentha spicata L.), one of the best-known mints, is an aromatic plant belonging to the Lamiaceae family. Spearmint is cultivated commercially throughout the world, and the ground fresh biomass and dried leaves of the plant are used as a spice and in herbal teas. In addition, spearmint has been generally recognized to be safe in regular diets and can be safely consumed (Telci et al., 2010). Spearmint is a creeping rhizomatous, glabrous, and herbaceous perennial plant with a pungent smell. The plant is known to grow well in moist habitats such as swamps or creeks, where the soil is sand or clay, and in sunny to partly sunny conditions (Chrysargyris et al., 2017). However, extreme environmental conditions are often found on rooftops, including rapid heating from the sun, large temperature changes between day and night, strong winds, and dramatic fluctuations in water availability (Nagase and Dunnett, 2010). These factors present great challenges in sustaining herb growth on green roofs, especially in temperate climates.

Therefore, the purpose of our study was to assess the effects of different concentrations of hydrogel in various green roof substrates on spearmint growth and flowering parameters depending on precipitation in a rooftop garden.

\section{Materials and Methods}

Rooftop experimental setup. In general, temperature and precipitation have a major impact on plant growth and survival. South Korea has four seasons, with an average temperature of 10 to $15^{\circ} \mathrm{C}$ per year and an average rainfall of 1200 to $1500 \mathrm{~mm}$ per year. Rainfall mainly occurs in the summer, with spring, autumn, and winter being generally dry (Kim et al., 2020). During the experimental period, diurnal maximum air temperature ranged from 31.0 to $35.3^{\circ} \mathrm{C}$, and the minimum air temperature ranged from 4.6 to $17.4{ }^{\circ} \mathrm{C}$. The average monthly precipitation ranged from 24.6 to $277.7 \mathrm{~mm}$ (Fig. 1). The study site data on air temperature and precipitation during the experimental period indicated a relatively dry period around June, except for May, after planting. The most precipitation occurred in August (average precipitation, $277.7 \mathrm{~mm}$ ). Drought vs. rainy season was determined based on the precipitation on the green roof without supplemental irrigation (Ju et al., 2020).

Rooftop experiments were implemented on a roof platform at the Complex Practice Building of Konkuk University, Chungju, Chungcheongbuk-do, located at lat. $35^{\circ} 49^{\prime} \mathrm{N}$ and long. $127^{\circ} 08^{\prime} \mathrm{E}$. A total of 45 green roof square plots $(500 \mathrm{~mm}$ long $\times 500 \mathrm{~mm}$ wide $\times 250$ $\mathrm{mm}$ high) were filled with the following four layers: drainage layer, filter fabric, substrate, and vegetation, from bottom to top (Olszewski et al., 2010). The drainage layer was a $30-\mathrm{mm}$ thick drainage board $(500 \mathrm{~mm}$ long $\times 500 \mathrm{~mm}$ wide; Neo Percolation PET, KyungDong One 


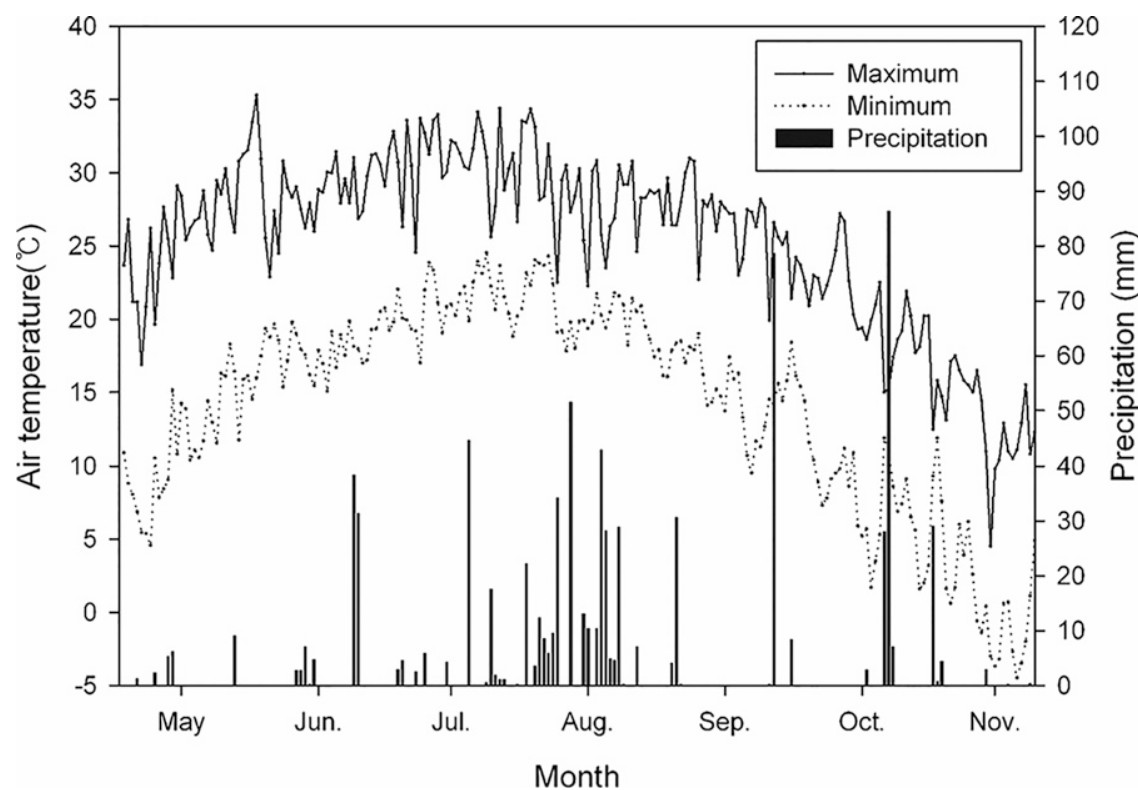

Fig. 1. Diurnal air temperatures (minimum and maximum) and precipitation recorded at the study site during the experimental period between May and November.

Co. Ltd., Seoul, South Korea), with a high-impact polystyrene dimple sheet used to support the three layers above, to increase insulation, and to retain excess water. A nonwoven geotextile fabric (Neo Percolation sheet, KyungDong One Co. Ltd.) was bonded to the upper surface of the drainage board as the filter layer, which prevented the small particles from being washed from the substrate layer out of the system. The growing medium and plants were added and planted on top of the nonwoven geotextile (Ju et al., 2020).

Although a maximum of $15 \%$ (Rowe et al., 2006) organic matter content is recommended for green roof substrates, the current field experiment was focused on the effect of substrate components on the growth and flowering of spearmint. Thus, three substrates were formulated with coconut coir dust (FIBROSOIL, Jayampathi Lanka Exports, Pvt. Ltd., Kurunegala, Sri Lanka) (as organic matter) and perlite (PARASO, KyungDong One Co. Ltd.) (as inorganic matter) at ratios of $80 \%$ to $20 \%\left(\mathrm{v} / \mathrm{v} ; \mathrm{C}_{4} \mathrm{P}_{1}\right), 50 \%$ to $50 \%$ $\left(\mathrm{C}_{1} \mathrm{P}_{1}\right)$, or $20 \%$ to $80 \%\left(\mathrm{C}_{1} \mathrm{P}_{4}\right)$. All substrates were prepared in $250-\mathrm{L}$ oval rubber basins. The physicochemical properties of the three substrates used in the experiments are shown in Table 1.

Hydrogel, acrylic acid-sodium acrylate copolymer (purity, $\geq 94 \%$; $\mathrm{pH}, 7.35$; density, $0.72 \mathrm{~g} \cdot \mathrm{cm}^{-3}$; moisture content, $1.66 \%$ ) (K-SAM, Kolon Chemical Co., Ltd., Seoul, South Korea) was incorporated into the substrates at concentrations of 0 (control), 0.25 , $0.5,1.0$, or $2.0 \mathrm{~kg} \cdot \mathrm{m}^{-3}$ dry weight basis. The visual rating were also determined in June (drought season). Visual ratings were assessed by a relative plant appearance score based on a 1 to 5 grade: $1=$ severely stressed and completely dried out; 2 = stressed with less than $50 \%$ of the leaves retaining green pigmentation; $3=$ mildly stressed with $50 \%$ of the leaves retaining green pigmentation; $4=\mathrm{mi}-$ nor stress with over $50 \%$ of the leaves appearing to be healthy; and $5=$ unstressed with all leaves appearing healthy (Nagase and Dunnett, 2010). Leaf color, chlorophyll content of the leaves and number of inflorescences were recorded as growth parameters in August (rainy season), when plants were at their peak flowering time. Leaf upper surface color was measured using a Chroma meter (CR-400; Konica Minolta Group, Osaka, Japan) and were recorded as lightness (L), red-green $\left(a^{*}\right)$, yellowblue ( $\left.b^{*}\right)$, chroma value (Chroma), and hue angle (Hue), with samples taken from the third leaf from the top of each plant (Treadwell et al., 2011). The chlorophyll contents of the leaves were measured in nine leaves per each square plot using a chlorophyll meter (SPAD502 m; Minolta Camera Co., Ltd, Osaka, Japan).

Statistical analysis. This experiment had a hree substrates were blended for 10 min in a soil mixer with each hydrogel concentration and $5 \%$ (by volume) organic fertilizer (TOCHAN, DooHo LandTech., Seoul, South Korea). Fifteen treatments and three replications per each substrate and hydrogel combination were installed in 45 rooftop plots at a media depth of $20 \mathrm{~cm}$.

Plant material and growth analyses. Spearmint (Mentha spicata) was selected because of its popularity in many industries and its growth habits, such as high sensitivity to moisture stress and the need for regular irrigation. Three spearmint plants with heights of about 8 to $9 \mathrm{~cm}$ were transplanted in each green roof square plot $(3$ plants $\times 45$ square plots) during late spring. The initial height of the transplants differed by less than $1 \mathrm{~cm}$. Each plot was irrigated thoroughly with $10 \mathrm{~L}$ water using a water sprinkler can after transplanting to ensure the plants were well established and media were uniformly wet. Afterward, they were watered every $2 \mathrm{~d}$ for the first week only, then allowed to grow without watering or irrigation to assess the influence of hydrogels on substrates during drought and rainy seasons under for the remaining experimental period. Plant height $(H)$ above the stem base, width at the widest vegetative point of the plant passing through the center $\left(W_{1}\right)$, and the widest width perpendicular to $W_{1}\left(W_{2}\right)$ were measured. The data on height and width were used to calculate the growth index as $\left[\left(W_{1}+W_{2}\right) / 2+H\right] / 2$, which is commonly used as an indicator of plant size (Hammond et al., 2007). The length and width of the leaves, number of leaves, and factorial design with three different substrates $\left(\mathrm{C}_{4} \mathrm{P}_{1}, \mathrm{C}_{1} \mathrm{P}_{1}\right.$, and $\left.\mathrm{C}_{1} \mathrm{P}_{4}\right)$ and five different amounts of hydrogel addition $(0,0.25,0.5$, 1.0 , and $\left.2.0 \mathrm{~kg} \cdot \mathrm{m}^{-3}\right)$. There were three replicates for each treatment $(15 \times 3)$, and each replicate consisted of three plants $(15 \times 3 \times$ $3)$. Statistical analyses were performed using SPSS statistical software (version 18.0; SPSS Inc., Chicago, IL), and SigmaPlot (version 10.0; Systat Software, Inc., Chicago, IL) was used for graph module analyses. The effect of substrate and hydrogel on the growth and flowering parameters of spearmint were analyzed using one-way analysis of variance. Significant differences between treatment means were determined using Duncan's multiple range tests $(P<0.05)$. Regression analysis was performed to investigate the relationship between different substrates and hydrogel concentrations.

\section{Results and Discussion}

Plant height, leaf number, leaf width, and visual ratings of spearmint (Mentha spicata) were significantly greater when grown in a $\mathrm{C}_{4} \mathrm{P}_{1}$ coir-based substrate compared with the other two substrates. In $\mathrm{C}_{1} \mathrm{P}_{4}$, leaf length and the growth index of spearmint were significantly less than plants grown in $\mathrm{C}_{1} \mathrm{P}_{1}$ and $\mathrm{C}_{4} \mathrm{P}_{1}$ when they were measured in June (less rainfall). The addition of $2.0 \mathrm{~kg} \cdot \mathrm{m}^{-3}$ hydrogel in these three substrates resulted in an increased number of leaves and improved visual ratings. There was an interaction effect between the

Table 1. Physicochemical properties of three substrates used in the rooftop garden.

\begin{tabular}{lccccc}
\hline Substrates & Acidity $(\mathrm{pH})$ & Electronic conductivity $\left(\mathrm{dS} \cdot \mathrm{m}^{-1}\right)$ & Air-filled porosity $(\%)$ & Water holding capacity $(\%)$ & Bulk density $\left(\mathrm{g} \cdot \mathrm{cm}^{-3}\right)$ \\
\hline $\mathrm{C}_{4} \mathrm{P}_{1}{ }^{\mathrm{Z}}$ & 6.41 & 0.47 & 7.4 & 68.9 & 0.08 \\
$\mathrm{C}_{1} \mathrm{P}_{1}$ & 6.41 & 0.44 & 7.9 & 59.4 & 0.08 \\
$\mathrm{C}_{1} \mathrm{P}_{4}$ & 7.06 & 0.11 & 16.2 & 45.0 & 0.11 \\
\hline
\end{tabular}

${ }^{{ }^{z}} C_{4} \mathrm{P}_{1}=$ coir $80 \%$, perlite $20 \% ; C_{1} \mathrm{P}_{1}=$ coir $50 \%$, perlite $50 \% ; \mathrm{C}_{1} \mathrm{P}_{4}=$ coir $20 \%$, perlite $80 \%$ (percentage by vol.), dry weight basis. 
Table 2. Plant characteristics, growth index, and visual ratings of spearmint (Mentha spicata) measured in June (dry season).

\begin{tabular}{|c|c|c|c|c|c|c|c|}
\hline Substrates & Hydrogel treatments $\left(\mathrm{kg} \cdot \mathrm{m}^{-3}\right)$ & Plant ht $(\mathrm{cm})$ & Leaf no. (per plant) & Leaf length $(\mathrm{mm})$ & Leaf width $(\mathrm{mm})$ & Growth index & Visual rating $^{z}$ \\
\hline \multirow[t]{3}{*}{$\overline{\mathrm{C}_{4} \mathrm{P}_{1}{ }^{\mathrm{y}}}$} & Control & $17.38 \mathrm{a}-\mathrm{d}^{\mathrm{x}}$ & $139.0 \mathrm{~b}$ & $40.82 \mathrm{~b}-\mathrm{e}$ & $26.03 \mathrm{a}-\mathrm{d}$ & $16.96 \mathrm{a}-\mathrm{d}$ & $2.9 \mathrm{a}-\mathrm{c}$ \\
\hline & 0.5 & $19.40 \mathrm{a}$ & $135.5 \mathrm{~b}$ & $46.53 \mathrm{ab}$ & $29.23 \mathrm{a}$ & $18.24 \mathrm{ab}$ & $2.9 \mathrm{a}-\mathrm{c}$ \\
\hline & 1.0 & $19.03 \mathrm{a}$ & $141.0 \mathrm{~b}$ & $44.98 \mathrm{a}-\mathrm{c}$ & $26.47 \mathrm{a}-\mathrm{c}$ & $17.95 \mathrm{ab}$ & $3.0 \mathrm{ab}$ \\
\hline \multirow[t]{3}{*}{$\mathrm{C}_{1} \mathrm{P}_{1}$} & Control & $18.50 \mathrm{ab}$ & $114.3 \mathrm{~cd}$ & $48.06 \mathrm{a}$ & $28.93 \mathrm{a}$ & $18.96 \mathrm{a}$ & $2.5 \mathrm{~b}-\mathrm{d}$ \\
\hline & 0.25 & $16.55 \mathrm{~b}-\mathrm{e}$ & $114.5 \mathrm{~cd}$ & $42.85 \mathrm{a}-\mathrm{e}$ & $26.11 \mathrm{a}-\mathrm{d}$ & $17.36 \mathrm{a}-\mathrm{d}$ & $2.7 \mathrm{bc}$ \\
\hline & 0.5 & $15.27 \mathrm{de}$ & $107.3 \mathrm{~d}$ & $40.77 \mathrm{~b}-\mathrm{e}$ & $23.19 \mathrm{~d}-\mathrm{f}$ & $15.82 \mathrm{c}-\mathrm{e}$ & $2.8 \mathrm{a}-\mathrm{c}$ \\
\hline \multirow[t]{5}{*}{$\mathrm{C}_{1} \mathrm{P}_{4}$} & Control & $15.18 \mathrm{de}$ & $133.7 \mathrm{bc}$ & $37.55 \mathrm{de}$ & $24.37 \mathrm{c}-\mathrm{f}$ & $16.28 \mathrm{~b}-\mathrm{e}$ & $1.4 \mathrm{e}$ \\
\hline & 0.25 & $14.45 \mathrm{e}$ & $126.0 \mathrm{~b}-\mathrm{d}$ & $41.03 \mathrm{~b}-\mathrm{e}$ & $25.12 \mathrm{~b}-\mathrm{e}$ & $15.37 \mathrm{de}$ & $2.3 \mathrm{~cd}$ \\
\hline & 0.5 & $14.60 \mathrm{e}$ & $130.5 \mathrm{bc}$ & 36.95 e & $21.27 \mathrm{f}$ & $14.84 \mathrm{e}$ & $2.0 \mathrm{~d}$ \\
\hline & 1.0 & $15.95 \mathrm{c}-\mathrm{e}$ & $123.8 \mathrm{~b}-\mathrm{d}$ & $39.03 \mathrm{c}-\mathrm{e}$ & 22.82 ef & $15.85 \mathrm{c}-\mathrm{e}$ & $2.7 \mathrm{bc}$ \\
\hline & 2.0 & $14.18 \mathrm{e}$ & $135.5 \mathrm{~b}$ & $40.24 \mathrm{c}-\mathrm{e}$ & $24.32 \mathrm{c}-\mathrm{f}$ & $14.88 \mathrm{e}$ & $2.8 \mathrm{a}-\mathrm{c}$ \\
\hline \multirow[t]{2}{*}{ Significance } & Substrate & $* * *$ & $* * *$ & $* * *$ & *** & $* * *$ & $* * *$ \\
\hline & Hydrogel & NS & * & NS & $* *$ & NS & $* * *$ \\
\hline
\end{tabular}

${ }^{\mathrm{z}}$ Visual ratings is the scale of a relative plant appearance score based on a 1-5 grade: $1=$ severely stressed and completely dried out; $2=$ stressed with less than $50 \%$ of the leaves retaining green pigmentation; $3=$ mildly stressed with $50 \%$ of the leaves retaining green pigmentation; $4=$ minor stress with over $50 \%$ of the leaves appearing to be healthy; and $5=$ unstressed with all leaves appearing healthy.

${ }^{\mathrm{y}} \mathrm{C}_{4} \mathrm{P}_{1}=$ coir $80 \%$, perlite $20 \% ; \mathrm{C}_{1} \mathrm{P}_{1}=$ coir $50 \%$, perlite $50 \% ; \mathrm{C}_{1} \mathrm{P}_{4}=$ coir $20 \%$, perlite $80 \%$ (percentage by vol.) supplemented with five concentrations of hydrophilic polymer: 0 (control), $0.25,0.5,1.0$, and $2.0 \mathrm{~kg} \cdot \mathrm{m}^{-3}$; polymer: medium $(\mathrm{w} / \mathrm{v})$, dry weight basis.

${ }^{x}$ Means within columns by substrate were determined by Duncan's multiple range test at the $P<0.05$ level. Ns, *,****Nonsignificant or significant at $P<0.05,0.01$, or 0.001 , respectively.

Table 3. Color measurements and chlorophyll soil-plant analysis development (SPAD) values of spearmint (Mentha spicata) grown in three different substrates with different amounts of hydrogel additions on green roofs in August (rainy season).

\begin{tabular}{|c|c|c|c|c|c|c|c|}
\hline \multirow[b]{2}{*}{ Substrates } & \multirow[b]{2}{*}{ Hydrogel treatments $\left(\mathrm{kg} \cdot \mathrm{m}^{-3}\right)$} & \multicolumn{5}{|c|}{ Chroma meter mode } & \multirow[b]{2}{*}{ SPAD value } \\
\hline & & $\mathrm{L}^{\mathrm{z}}$ & $a^{*}$ & $b^{*}$ & Chroma & Hue & \\
\hline \multirow[t]{5}{*}{$\overline{\mathrm{C}_{4} \mathrm{P}_{1}^{\mathrm{y}}}$} & Control & $46.3 a-d^{x}$ & $-18.4 \mathrm{ab}$ & $32.8 \mathrm{a}-\mathrm{d}$ & $37.6 \mathrm{a}-\mathrm{c}$ & $119.2 \mathrm{~b}-\mathrm{d}$ & $27.7 \mathrm{gh}$ \\
\hline & 0.25 & $46.7 \mathrm{a}-\mathrm{c}$ & $-18.8 \mathrm{ab}$ & $36.7 \mathrm{a}$ & $41.2 \mathrm{a}$ & $117.1 \mathrm{e}$ & $27.6 \mathrm{gh}$ \\
\hline & 0.5 & $46.6 \mathrm{a}-\mathrm{c}$ & $-18.2 \mathrm{ab}$ & $34.3 \mathrm{a}-\mathrm{c}$ & $38.9 \mathrm{a}-\mathrm{c}$ & $118.0 \mathrm{de}$ & $29.2 \mathrm{e}-\mathrm{g}$ \\
\hline & 1.0 & $46.1 \mathrm{a}-\mathrm{e}$ & $-18.3 \mathrm{ab}$ & $32.9 \mathrm{a}-\mathrm{d}$ & $37.7 \mathrm{a}-\mathrm{c}$ & $119.1 \mathrm{c}-\mathrm{e}$ & $28.8 \mathrm{fg}$ \\
\hline & 2.0 & $47.2 \mathrm{a}$ & $-18.6 \mathrm{ab}$ & $35.0 \mathrm{ab}$ & $39.6 \mathrm{ab}$ & $118.0 \mathrm{de}$ & $25.9 \mathrm{~h}$ \\
\hline \multirow[t]{5}{*}{$\mathrm{C}_{1} \mathrm{P}_{1}$} & Control & $45.0 \mathrm{a}-\mathrm{e}$ & $-18.7 \mathrm{ab}$ & $33.9 \mathrm{a}-\mathrm{d}$ & $38.6 \mathrm{a}-\mathrm{c}$ & $118.9 \mathrm{c}-\mathrm{e}$ & $31.2 \mathrm{c}-\mathrm{e}$ \\
\hline & 0.25 & $46.0 \mathrm{a}-\mathrm{e}$ & $-19.2 \mathrm{~b}$ & $31.6 \mathrm{~b}-\mathrm{d}$ & $37.0 \mathrm{a}-\mathrm{c}$ & $121.4 \mathrm{a}$ & $30.7 \mathrm{c}-\mathrm{f}$ \\
\hline & 0.5 & $47.1 \mathrm{ab}$ & $-18.9 \mathrm{ab}$ & $32.1 \mathrm{a}-\mathrm{d}$ & $37.3 \mathrm{a}-\mathrm{c}$ & $120.5 \mathrm{a}-\mathrm{c}$ & $29.4 \mathrm{e}-\mathrm{g}$ \\
\hline & 1.0 & $47.3 \mathrm{a}$ & $-19.3 \mathrm{~b}$ & $33.7 \mathrm{a}-\mathrm{d}$ & $38.9 \mathrm{a}-\mathrm{c}$ & $119.8 \mathrm{a}-\mathrm{d}$ & $29.9 \mathrm{~d}-\mathrm{f}$ \\
\hline & 2.0 & $43.6 \mathrm{c}-\mathrm{e}$ & $-17.9 \mathrm{ab}$ & $29.4 \mathrm{~d}$ & $34.4 \mathrm{c}$ & $121.3 \mathrm{ab}$ & $30.3 \mathrm{~d}-\mathrm{f}$ \\
\hline \multirow[t]{5}{*}{$\mathrm{C}_{1} \mathrm{P}_{4}$} & Control & $43.7 \mathrm{e}$ & $-18.0 \mathrm{ab}$ & $30.9 \mathrm{~b}-\mathrm{d}$ & $35.8 \mathrm{bc}$ & $120.2 \mathrm{a}-\mathrm{c}$ & $32.6 \mathrm{a}-\mathrm{c}$ \\
\hline & 0.25 & $43.9 \mathrm{de}$ & $-17.6 \mathrm{a}$ & $30.2 \mathrm{~cd}$ & $35.0 \mathrm{bc}$ & $120.2 \mathrm{a}-\mathrm{c}$ & $34.1 \mathrm{a}$ \\
\hline & 0.5 & $43.8 \mathrm{de}$ & $-17.4 \mathrm{a}$ & $30.4 \mathrm{~b}-\mathrm{d}$ & $35.1 \mathrm{bc}$ & $119.8 \mathrm{a}-\mathrm{d}$ & $31.8 \mathrm{bc}$ \\
\hline & 1.0 & $45.8 \mathrm{a}-\mathrm{e}$ & $-18.3 \mathrm{ab}$ & $32.8 \mathrm{a}-\mathrm{d}$ & $37.6 \mathrm{a}-\mathrm{c}$ & $119.2 b-d$ & $33.6 \mathrm{ab}$ \\
\hline & 2.0 & $44.4 \mathrm{~b}-\mathrm{e}$ & $-18.7 \mathrm{ab}$ & $33.3 \mathrm{a}-\mathrm{d}$ & $38.2 \mathrm{a}-\mathrm{c}$ & $119.4 \mathrm{a}-\mathrm{d}$ & $33.4 \mathrm{ab}$ \\
\hline \multirow[t]{3}{*}{ Significance } & Substrate & $* * *$ & $*$ & $* *$ & $*$ & $* * *$ & $* * *$ \\
\hline & Polymer rate & NS & NS & NS & NS & NS & NS \\
\hline & Interaction & NS & NS & NS & NS & $*$ & $*$ \\
\hline
\end{tabular}

${ }^{\mathrm{z} C o l o r}$ values were displayed as $\mathrm{L}, \mathrm{a}^{*}$, and $\mathrm{b}^{*}$ values, representing a light-dark spectrum with a range of 0 (black) to 100 (white), the green-red spectrum with a range of -60 (green) to +60 (red), and the blue-yellow spectrum with a range of -60 (blue) to +60 (yellow) dimensions respectively. Chroma $\left[\right.$ Chroma $=\left(\mathrm{a}^{* 2}+\mathrm{b}^{* 2}\right)^{1 / 2}$ ] and Hue angle $\left(\right.$ Hue $=\tan ^{-1} \mathrm{~b}^{\left.* / \mathrm{a}^{*}\right)}$ were calculated from $\mathrm{a}^{*}$ and $\mathrm{b}^{*}$ values.

${ }^{y} \mathrm{C}_{4} \mathrm{P}_{1}=$ coir $80 \%$, perlite $20 \% ; \mathrm{C}_{1} \mathrm{P}_{1}=$ coir $50 \%$, perlite $50 \% ; \mathrm{C}_{1} \mathrm{P}_{4}=$ coir $20 \%$, perlite $80 \%$ (percentage by vol.) supplemented with five concentrations of hydrophilic polymer: 0 (control), $0.25,0.5,1.0$, and $2.0 \mathrm{~kg} \cdot \mathrm{m}^{-3}$; polymer: medium (w/v), dry weight basis.

${ }^{x}$ Means within columns by substrate were determined by Duncan's multiple range test at the $P<0.05$ level. Ns, $*, * * * * *$ Nonsignificant or significant at $P<0.05,0.01$, or 0.001 , respectively.

substrate and hydrogel concentration on leaf length $(P=0.028)$ and the growth index $(P=$ 0.049 ) (Table 2). In our green roof experiment, there was a drought period of 1 month, with hot weather soon after planting. These weather conditions might have led to a rapid decline in the moisture content of the substrates. The $\mathrm{C}_{4} \mathrm{P}_{1}$ and $\mathrm{C}_{1} \mathrm{P}_{1}$ substrates, which contained more coir, would have been able to hold more water to maintain the structural integrity of plants and supply more nutrients than the perlite-based substrate $\mathrm{C}_{1} \mathrm{P}_{4}$ under these drought conditions. Actually, the physicochemical properties were similar between substrates $\mathrm{C}_{4} \mathrm{P}_{1}$ and $\mathrm{C}_{1} \mathrm{P}_{1}$, except for water holding capacity. By contrast, acidity, air-filled porosity, and bulk density were the greatest in $\mathrm{C}_{1} \mathrm{P}_{4}$ (Table 1). It has been suggested that a substrate with a high coir content can increase the growth of spearmint during the drought season (Savi et al., 2014). Although water holding capacity of hydrogel may be affected by the substrate component (Olszewski et al., 2010), in general, hydrogel addition increased the average volumetric water content in all substrates (Xu et al., 2018). Akhter et al. (2004) reported that the addition of hydrogels could slow down soil moisture loss and delay the wilting time of seedlings by 4 to $5 \mathrm{~d}$. In accordance with these previous studies, we found that spearmint grown in the coir-based substrate $\mathrm{C}_{4} \mathrm{P}_{1}$ presented increased growth with hydrogel addition, especially at a concentration of 2.0 $\mathrm{kg} \cdot \mathrm{m}^{-3}$. This result suggests that the capacity 


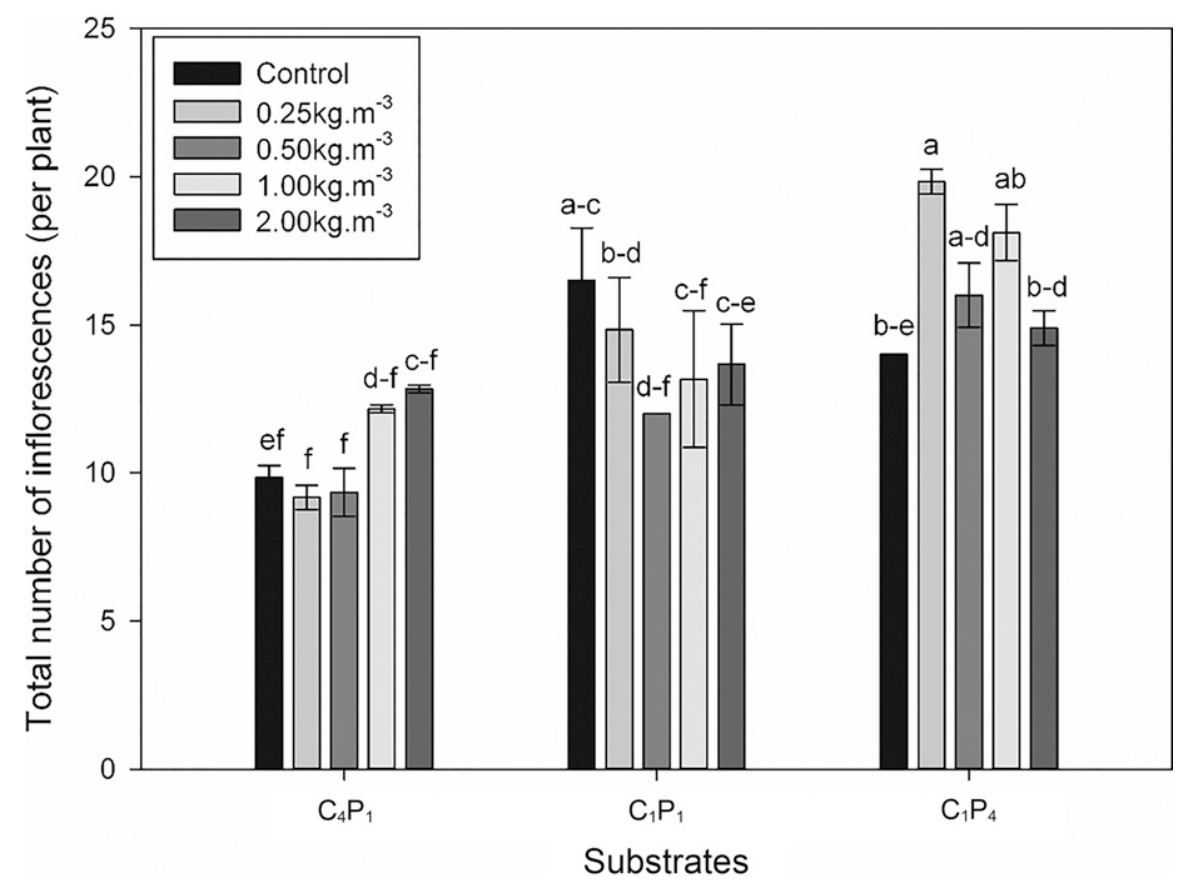

Fig. 2. Effect of total number of inflorescences per spearmint (Mentha spicata) grown in three different ratios of substrates added with different amounts of hydrogels on green roofs in August (rainy season). Different letters indicate significant differences following Duncan's multiple range test at the $P<0.05$ level. Data represent mean $\pm \mathrm{SE}(\mathrm{n}=9) . \mathrm{C}_{4} \mathrm{P}_{1}$, coir $80 \%$ and perlite $20 \% ; \mathrm{C}_{1} \mathrm{P}_{1}$, coir $50 \%$ and perlite $50 \% ; \mathrm{C}_{1} \mathrm{P}_{4}$, coir $20 \%$ and perlite $80 \%$ (percentage by volume).

for water retention of the substrate and the efficiency of water use may increase with the addition of hydrogels during the drought season, as reported by Bai et al. (2010).

On the other hand, during the rainy season, spearmint Hue values increased with decreasing coir content whereas $\mathrm{L}, \mathrm{a}^{*}, \mathrm{~b}^{*}$, and Chroma values decreased, indicating that the leaves were slightly less green. Therefore, the leaves of spearmint grown in $\mathrm{C}_{4} \mathrm{P}_{1}$ with the greatest coir content had brighter, more yellowish, and yellow-greenish leaves than those grown in the other two substrates. In addition, there was no influence of hydrogel concentration during the rainy season. There was an interaction between the substrate and hydrogel concentration on Hue $(P=0.040)$ and chlorophyll soil-plant analysis development (SPAD) values $(P=0.021)$ of spearmint, with significantly lower Hue and relative chlorophyll contents in coir-based substrate $\mathrm{C}_{4} \mathrm{P}_{1}$ than in the other substrates (Table 3 ). Leaf color and greenness are an efficient indicator of quality and stress on plants (Netto et al., 2005; Treadwell et al., 2011). In general, leaf photosynthesis is affected by the chlorophyll content and chloroplast structure (Zhao et al., 2001). In August, during the rainy season, there was heavy rainfall that may have caused waterlogging of the substrate, thereby affecting leaf color and chlorophyll content.

The total number of inflorescences per plant of the spearmint grown in perlite-based substrate $\mathrm{C}_{1} \mathrm{P}_{4}$ was significantly greater than that grown in coir-based $\mathrm{C}_{4} \mathrm{P}_{1}$ and $\mathrm{C}_{1} \mathrm{P}_{1}$. For substrate $\mathrm{C}_{1} \mathrm{P}_{4}$, the total number of inflorescences per spearmint was 1.55 - and 1.18-fold was significantly greater $(P<0.05)$ than that grown in $\mathrm{C}_{4} \mathrm{P}_{1}$ and $\mathrm{C}_{1} \mathrm{P}_{1}$ with less perlite. Our study results indicate that the perlite-based substrate $\mathrm{C}_{1} \mathrm{P}_{4}$ with hydrogel additive is suitable for enhancing spearmint growth and flowering in rooftop gardens regardless of seasonal precipitation. Hydrogel application can vary by the local climate as well as the substrate components under no-irrigation green roofs. Overall, hydrogel addition in green roof substrates could expand the selection of various plants in dry climates and improve substrate rainwater retention. Future research should evaluate the growth response of various other groundcover plants and the long-term effect of water retention additives in green roofs substrates to improve the diversity and longevity of the vegetation grown in rooftop gardens.

\section{Literature Cited}

Akhter, J., K. Mahmood, K.A. Malik, A. Mardan, M. Ahmad, and M.M. Iqbal. 2004. Effects of hydrogel amendment on water storage of sandy loam and loam soils and seedling growth of barley, wheat and chickpea. Plant Soil Environ. 50:463-469, doi: 10.17221/4059-PSE

Apostol, K.G., D.F. Jacobs, and R.K. Dumroese. 2009. Root desiccation and drought stress responses of bareroot Quercus rubra seedlings treated with a hydrophilic polymer root dip. Plant Soil 315:229-240, doi: 10.1007/s11104008-9746-6.

Bai, W., H. Zhang, B. Liu, Y. Wu, and J. Song. 2010. Effects of super-absorbent polymers on the physical and chemical properties of soil following different wetting and drying cycles. Soil Use Mgt. 26:253-260, doi: 10.1111/ j.1475-2743.2010.00271.x

Chrysargyris, A., E. Nikolaidu, A. Stamatakis, and N. Tzortzakis. 2017. Vegetative, physiological, nutritional and antioxidant behavior of spearmint (Mentha spicata L.) in response to different nitrogen supply in hydroponics. J. Appl. Res. Med. Aromat. Plants 6:52-61, doi: 10.1016/j.jarmap.2017.01.006.

Farrell, C., X.Q. Ang, and J.P. Rayner. 2013. Waterretention additives increase plant available water in green roof substrates. Ecol. Eng. 52:112-118, doi: 10.1016/j.ecoleng.2012.12.098.

Fatemeh, K. and M. Ruzica. 2017. Review on the roles and effects of growing media on plant performance in green roofs in world climates. Urban For. Urban Green. 23:13-26, doi: 10.1016/j.ufug.2017.02.006.

Getter, K.L. and D.B. Rowe. 2006. The role of extensive green roofs in sustainable development. HortScience 41:1276-1285, doi: 10.21273/ HORTSCI.41.5.1276.

Hammond, H.E., J.G. Norcini, S.B. Wilson, R.K Schoellhorn, and D.L. Miller. 2007. Growth, flowering, and survival of firewheel Gaaillardia pulchella Foug. based on seed source and growing location. Native Plants J. 8:25-39, doi: 10.2979/NPJ.2007.8.1.25.

Ju, J.H., H. Xu, K.J. Yeum, and Y.H. Yoon. 2020. Effects of hydrophilic polymer on the survival, growth, and flowering characteristics of pineapple sage (Salvia elegans) in unirrigated green roofs. Appl. Ecol. Environ. Res. 18:3887-3896, doi: 10.15666/aeer/1803.38873896.

Kim, J.Y., D.K. Lee, and H.G. Kim. 2020. Suitable trees for urban landscapes in the republic of Korea under climate change. Landsc. Urban Plan. 204: 103037, doi: 10.1016/j.landurbplan.2020.103937. 
Mastura, S., F.A. Md, and U.H. Md. 2017. Present practice and future prospect of rooftop farming in Dhaka city: A step towards urban sustainability. J. Urban Mgt. 6:56-65, doi: 10.1016/ J.JUM.2017.12.001.

Nagase, A. and N. Dunnett. 2010. Drought tolerance in different vegetation types for extensive green roofs: Effects of watering and diversity. Landsc. Urban Plan. 97:318-327, doi: 10.1016/ j.landurbplan.2010.07.005

Netto, A.T., E. Campostrini, J.G. de Oliveira, and R.E. Bressan-Smith. 2005. Photosynthetic pigments, nitrogen, chlorophyll a fluorescence and SPAD-502 readings in coffee leaves. Scientia Hort. 104:199-209, doi: 10.1016/j.scienta.2004. 08.013 .

Olszewski, M.W., M.H. Holmes, and C.A. Young. 2010. Assessment of physical properties and stonecrop growth in green roof substrates amended with compost and hydrogel. HortTechnology 20: 438-444, doi: 10.21273/HORTTECH.20.2.438.

Orikiriza, L.J.B., H. Agaba, G. Eilu, J.D. Kabasa, M. Worbes, and A. Hüttermann. 2013. Effects of hydrogels on tree seedling performance in temper- ate soils before and after water stress. J. Environ. Prot. 4:713-721, doi: 10.4236/jep.2013.47082.

Rowe, D.B., M.A. Monterusso, and C.L. Rugh 2006. Assessment of heat-expanded slate and fertility requirements in green roof substrates. HortTechnology 16:471-477, doi: 10.21273/ HORTTECH.16.3.0471.

Savi, T., D. Boldrin, M. Marin, V.L. Love, S. Andri, M. Tretiach, and A. Nardini. 2015. Does shallow substrate improve water status of plants growing on green roofs? Testing the paradox in two subMediterranean shrubs. Ecol. Eng. 84:292-300, doi: 10.1016/j.ecoleng.2015.09.036.

Savi, T., M. Marin, D. Boldrin, G. Incerti, S Andri, and A. Nardini. 2014. Green roofs for a drier world: Effects of hydrogel amendment on substrate and plant water status. Sci Total Environ. 490:467-476, doi: 10.1016/ j.scitotenv.2014.05.020.

Telci, I., I. Demirtas, E. Bayram, O. Arabaci, and O. Kacar. 2010. Environmental variation on aroma components of pulegone/piperitone rich spearmint (Menta spicata L.). Ind. Crops Prod. 32 588-592, doi: 10.1016/j.indcrop.2010.07.009.
Tomadoni B., M.F. Salcedo, A.Y. Mansilla, C.A. Casalongué, and V.A. Alvarez. Macroporous alginate-based hydrogels to control soil substrate moisture: Effect on lettuce plants under drought stress. Eur. Polym. J. 137:109953, doi: 10.1016/j.eurpolymj.2020.109953.

Treadwell, D.D., G.J. Hochmuth, R.C. Hochmuth, E.H. Simonne, S.A. Sargent, L.L. Davis, W.L. Laughlin, and A. Berry. 2011. Organic fertilization programs for greenhouse fresh-cut basil and spearmint in a soilless media trough system. HortTechnology 21:162-169, doi: 10.21273/HORTTECH.21.2.162.

Xu, H., G.J. Yeum, Y.H. Yoon, and J.J. Ju. 2018. Effect of hydrophilic polymer in three green roof substrates on growth, flower development, and overwintering of Agastache rugosa (Korean mint) without irrigation. Appl. Ecol. Environ. Res. 16: 5503-5516, doi: 10.15666/aeer/1605.55035516.

Zhao, D., D.M. Oosterhuis, and C.W. Bednarz. 2001. Influence of potassium deficiency on photosynthesis, chlorophyll content, and chloroplast ultrastructure of cotton plants. Photosynthetica 39:103-109, doi: 10.1023/A:1012404204910. 